\title{
Effect of Preparation Methods on the Composition and Structure of Dietary Fiber from Bamboo Shoot
}

\author{
Huang Xiao-bing \\ Agricultural Products Processing Research Institute, \\ Chinese Academy of Tropical Agricultural Sciences \\ Zhan Jiang, China \\ huang5102@hotmail.com
}

Peng Shao-dan

Agricultural Products Processing Research Institute, Chinese Academy of Tropical Agricultural Sciences Zhan Jiang, China

282387502@qq.com

\author{
Li Ji-hua \\ Agricultural Products Processing Research Institute, \\ Chinese Academy of Tropical Agricultural Sciences \\ Zhan Jiang, China \\ foodpaper@126.com \\ Lin Li-jing \\ Agricultural Products Processing Research Institute, \\ Chinese Academy of Tropical Agricultural Sciences \\ Zhan Jiang, China \\ 49031788@qq.com
}

\begin{abstract}
Objective: This study was conducted to evaluate the effects of different preparation methods on the quality of dietary fiber from bamboo shoot (BDF). Methods: Four methods including water-washing (WT), acid-base treatment (ABT), fermentation (FT) and enzyme treatment (ET) were carried out, and the composition, colour, water absorption index (WAI) and water solubility index (WSI) of BDF were determined as well as the structure characterized by scanning electron microscope (SEM) and fourier transform infrared (FT-IR) spectrometer. Results: The results showed that the highest contents of SDF, IDF and TDF were obtained with ET, which were $60.36 \pm 0.78 \%, 7.90 \pm 0.24 \%$, and $68.26 \pm 1.02 \%$, respectively. But the colour of dietary fiber by WT and FT could be protected well. The value of WAI was the highest for ABT, while ET had the highest WSI. The SEM images and infrared spectrometer analysis demonstrated that the preparations of FT and ET could produce porous and uniform dietary fiber with its composition complete. Conclusion: These results suggest that the FT and ET may be the environmental and efficient methods in the industry to preparing high quality of BDF.
\end{abstract}

Keywords- dietary fiber; fiber analysis; WAI; WSI; colour

\section{INTRODUCTION}

Bamboos, a group of giant arborescent grasses, belong to the family Poaceae and sub-family Bambuseae, which are mainly found in the mixed deciduous and tropical evergreen forests and partly found in the dry dipterocarps forest. More than 1250 species belonging to 75 genera are known to exist throughout the world ${ }^{[1]}$, out of which 500 species in 40 genera are recorded in China, mostly in the monsoon areas of south and southwest China ${ }^{[2]}$. Bamboo shoots are the new culms that just emerge from the ground and constitute a range of traditional delicacies in many countries. Being low in fat content and high in potassium, carbohydrate, dietary fibers, amino acids, Vitamins and active materials, bamboo shoots are consumed in raw, canned, boiled, marinated, fermented, frozen, liquid and medicinal forms ${ }^{[3-5]}$. As a traditional Chinese medicinal material for more than 2000 years in China, bamboo shoots were proclaimed to be beneficial to human health, by promoting motion and peristalsis of the intestine, helping digestion, and preventing and curing cardiovascular diseases and cancers according to archaic Chinese medicinal books, such as "Compendium of Materia Medica", etc. ${ }^{[6]}$. And most of the benefits to the human body are due to the high amounts of dietary fiber in Bamboo shoots (BDF), ranging from 2.23 to $4.20 \mathrm{~g} / 100 \mathrm{~g}$ fresh weight of shoot ${ }^{[7]}$. As a dietary fiber source, the shoots have beneficial effects on lipid profile and bowel function, so consumption of bamboo shoots with high levels of dietary fiber might help in preventing or delaying the onset of chronic diseases ${ }^{[8]}$. In addition, dietary fiber from bamboo shoot is cheap compared to that derived from wheat, oat, corn, potato, pea, soybean, and apples, which could generate economic benefits for companies using it in their products. Generally, there are four methods to prepare dietary fiber, including water-washing (WT), acid-base treatment (ABT), fermentation (FT) and enzyme treatment (ET). This study was intended to further investigate the effect of preparation methods of BDF on the DF composition, physicochemical properties such as colour, water absorption index (WAI) and water solubility index (WSI), microstructure, and molecular structure. These basic data would be helpful to large scale preparation and quality control of BDF.

\section{MATERIALS AND METHODS}

\section{A. Materials}

The bamboo shoots were collected after natural fermentation in sealed cans for 3 months about, and then rinsed with flowing water for $1 \mathrm{~h}$. The water on the surface was drained and the bamboo shoots were cut into pieces 
with a diameter of $1-2 \mathrm{~mm}$. The moisture content was determined as $86.27 \pm 0.36 \%$.

\section{B. BDF preparation}

\section{1) Water-washing treatment}

$200 \mathrm{~g}$ of bamboo shoot pieces were mixed with 400 $\mathrm{mL}$ of distilled water, and homogenized into slurry. And then the slurry was boiled for $20 \mathrm{~min}$ and filtered with 100 mesh nylon sieve, rinsed with water to neutral $\mathrm{pH}$. The residues were dried at $50^{\circ} \mathrm{C}$ to a constant weight, smashed with a grinder and the BDF was gathered with a 40 mesh sieve.

\section{2) Acid-base treatment}

$200 \mathrm{~g}$ of bamboo shoot pieces were hydrolyzed in 400 $\mathrm{mL}$ aqueous alkali at $\mathrm{pH} 12.0$ by addition of $1 \mathrm{M} \mathrm{NaOH}$, $60^{\circ} \mathrm{C}$ for $2 \mathrm{~h}$. The shoots were then rinsed with water to neutral $\mathrm{pH}$, and the water subsequently removed by centrifugation at $4000 \mathrm{rpm}$ for $10 \mathrm{~min}$. The dewatered shoots were digested in $400 \mathrm{~mL}$ acidic solution at $\mathrm{pH} 2.0$ by the addition of $1 \mathrm{M} \mathrm{HCl}, 60^{\circ} \mathrm{C}$ for $2 \mathrm{~h}$. Similarly, the acidic digested shoots were rinsed with water to neutral $\mathrm{pH}$, and then centrifuged at $4000 \mathrm{rpm}$ for $10 \mathrm{~min}$. After acidicbasic hydrolysis, the shoots were dried to a constant weight at $50^{\circ} \mathrm{C}$. Finally, the dried shoots were ground and collected with 40 mesh sieve.

\section{3) Fermentation}

$200 \mathrm{~g}$ of bamboo shoot pieces and $400 \mathrm{~mL}$ water were homogenized into slurry. $3 \%$ of skim milk powder and $0.5 \%$ of sucrose were added into the shoot slurry, which were transferred to conical flasks after stirring and dissolving. Then the slurry was autoclaved at $121^{\circ} \mathrm{C}$ for 10 min and cooled to room temperature. The fermentation was carried out in a constant temperature incubator for 24 $\mathrm{h}$ using a leaven consisted of Lactobacillus bulgaricus and Streptococcus thermophilus with ratio 1:1 (m:m). Finally, the slurry was filtered, rinsed and the residues were dried according to the methods mentioned above.

4) Enzyme treatment

$200 \mathrm{~g}$ of bamboo shoot pieces were homogenized into slurry with $400 \mathrm{~mL}$ water. For the process of enzyme deactivation, the slurry was boiled at $100^{\circ} \mathrm{C}$ for $20 \mathrm{~min}$. When cooled, the slurry was adjusted to temperature $60^{\circ} \mathrm{C}$ and $\mathrm{pH}$ 6.0, and $\alpha$-amylase (40-60 U/mg, Sinopharm Chemical Reagent Co., Ltd., Shanghai, China) was added by $1600 \mathrm{U} / \mathrm{g}$ shoots to hydrolyze for $2 \mathrm{~h}$. And the slurry was boiled to destroy enzyme once again. Then the papain (Enzyme activity $\geq 6000 \mathrm{U} / \mathrm{mg}$, Sinopharm Chemical Reagent Co., Ltd., Shanghai, China) was added by 3000 $\mathrm{U} / \mathrm{g}$ shoot to react for $2 \mathrm{~h}$ at $\mathrm{pH} 6.0$ around $60^{\circ} \mathrm{C}$. And then the slurry was filtered, rinsed, dried and smashed.

\section{Fiber composition analysis}

The Insoluble dietary fiber (IDF), soluble dietary fiber (SDF), and total dietary fiber (TDF) were determined using the Megazyme TDF Test Kit (K-TDFR, Megazyme International Ireland, Bray Business Park, Bray, Co. Wicklow, Ireland.) exactly according to enzymaticgravimetric method with MES-TRIS buffer, based on the AOAC991.43 ${ }^{[9]}$. Acid detergent fiber (ADF) and acid detergent lignin (ADL) were determined using the AOAC method $973.18^{[10]}$, whereas the NDF was determined using the method reported by van Soest et al. ${ }^{[11]}$.

\section{Colour determination}

The colour of BDF was determined using a Color i5 Benchtop Spectrophotometer with the CIE $L^{*}, a^{*}$ and $b^{*}$ colour scale (X-Rite, Incorporated, Grand Rapids, MI, USA). In this system, $L^{*}$ stands for the value of lightness, ranging from 0 (darkness) to 100 (brightness), $a^{*}$ ranges from -100 (greenness) to +100 (redness), and $b^{*}$ value ranges from -100 (blueness) to +100 (yellowness). The ground samples were packed evenly and smoothly into the colorimetric dish and placed in the spectrocolorimeter one at a time. The $L^{*}, a^{*}$ and $b^{*}$ values were obtained through the software ${ }^{[12]}$.

\section{E. WAI and WSI measurement}

$2.5 \mathrm{~g}$ of sample (weight marked as $m$ ) was then put in a centrifuge tube which weight was $m 0.30 \mathrm{~mL}$ of distilled water were added and stirred with sample to avoid lumps. The tubes were closed and placed in the water bath with $25^{\circ} \mathrm{C}$ for $20 \mathrm{~min}$. The tube was centrifuged at $5000 \mathrm{rpm}$ for $10 \mathrm{~min}$. The water was then poured out without loss of solids. Finally, the tube and residues were weighed as $m 1$. The WAI was calculated as following equation:

$$
W A I \%=100 \times(m 1-m 0) / m
$$

$2.5 \mathrm{~g}$ of sample $(\mathrm{m})$ were placed into a centrifuge tube, and then $30 \mathrm{~mL}$ of distilled water were added. The mixture was shaken for $5 \mathrm{~min}$, and then centrifuged at $5000 \mathrm{rpm}$ for $10 \mathrm{~min}$. The supernatant was poured into a moisture dish of known weight as $\mathrm{mO}$ and dehydrated overnight in the oven set at $40^{\circ} \mathrm{C}$. The dish was removed from the oven, and put in the desiccators to equilibrate. Finally, the dish with dried sample and lid were weighed as $m 1$. The WSI was calculated as:

$$
W S I \%=100 \times(m 1-m 0) / m
$$

\section{F. Microstructure analysis}

The BDF scanning electron images from extruded and untreated soybean residue were gathered using a scanning electron microscope (S-4800, Hitachi, Ltd., Tokyo, Japan). The SDF sample was prepared according to a previously described method ${ }^{[13]}$. Briefly, the samples were mounted and sputter-coated with a thin layer of gold-palladium alloy. Subsequently, each sample was transferred to the scanning electron microscope at an acceleration voltage of $3.0 \mathrm{kV}$ and magnifications of 2000 and 18,000.

\section{G. Fourier transform infrared spectroscopy}

The spectra of samples were obtained using fourier transform infrared (FT-IR) spectrometer (Spectrum GX FT-IR System, PerkinElmer Inc., Waltham, Massachusetts, USA). BDF was ground and mixed with $\mathrm{KBr}$, then pressed into transparent thin pellets. Spectra for FT-IR were from $4000-400 \mathrm{~cm}^{-1}$.

\section{H. Statistical analysis}

All values provided were the average of triplicate experiments. Analysis of variance (ANOVA) and Duncan's test were carried out, with confidence level of $95 \%(\mathrm{P}<0.05)$, using the software IBM SPSS Statistics 
20.0 (IBM Corporation, Armonk, New York, USA) to determine the significant difference of the results.

\section{RESULTS AND DISCUSSION}

\section{A. Composition of BDF}

The composition of BDF prepared from different methods was analyzed according to AOAC991.43 and AOAC973.18, respectively. The contents of SDF, IDF, and TDF in BDF were obtained from the former, while the content of cellulose, hemicellulose and lignin were determined with the latter. The results were listed in Table I. Among the four preparations, ET had the highest level of SDF IDF and TDF which were $7.90 \pm 0.24 \%, 60.36 \pm$ $0.78 \%, 68.26 \pm 1.02 \%$, respectively, followed by FT. The contents of SDF, IDF, and TDF in ABT were $3.07 \pm$ $0.30 \%, 42.05 \pm 0.54 \%, 45.12 \pm 0.84 \%$, respectively, with lowest content of TDF, while lowest content of SDF in WT was gained. As the severe hydrolysis of the acid-base treatment (ABT), the tissue was destroyed and some component such as hemicellulose was broken down into glucose, leading to the loss of TDF. WT would wash the soluble composition away like SDF, resulting in SDF reducing in WT. As to the results according to AOAC973.18, it was found that BDF had high level of hemicellulose followed by the cellulose, while only a little lignin was examined. But the lignin content as well as cellulose in ET was significantly higher than those in other preparations, which were $4.01 \%, 20.36 \%$, respectively.

TABLE I. THE EFFECT OF PREPARATION METHODS ON COMPOSITION OF BDF

\begin{tabular}{|l|c|c|c|}
\hline \multirow{2}{*}{$\begin{array}{c}\text { Preparation } \\
\text { Methods }\end{array}$} & \multicolumn{3}{|c|}{ AOAC991.43 } \\
\cline { 2 - 4 } WT & IDF & SDF & TDF \\
\hline ABT & $47.92 \pm 0.48 \%$ & $2.72 \pm 0.2 \%$ & $50.64 \pm 0.68 \%$ \\
\hline FT & $52.05 \pm 0.54 \%$ & $3.07 \pm 0.30 \%$ & $45.12 \pm 0.84 \%$ \\
\hline ET & $60.36 \pm 0.78 \%$ & $7.90 \pm 0.44 \%$ & $57.72 \pm 0.76 \%$ \\
\hline \multirow{2}{*}{$\begin{array}{c}\text { Preparation } \\
\text { Methods }\end{array}$} & Cellulose & AOAC 973.18 \\
\cline { 2 - 4 } WT & $17.12 \%$ & $47.35 \%$ & $68.26 \pm 1.02 \%$ \\
\hline ABT & $18.13 \%$ & $49.02 \%$ & $0.36 \%$ \\
\hline FT & $16.48 \%$ & $43.16 \%$ & $0.41 \%$ \\
\hline ET & $20.36 \%$ & $27.13 \%$ & $4.01 \%$ \\
\hline
\end{tabular}

\section{B. Physicochemical properties analysis of $B D F$}

\section{1) Colour}

The colour difference in different preparations of BDF was visually shown in Table II. The $L^{*}$ value is an indicator of brightness, and the brightness with high $L^{*}$ value in raw ingredients plays a crucial role in food development due to consumer preferences, especially in bakery products that claim to be good or excellent sources of DF. $L^{*}$ value in WT was $85.02 \pm 0.78$ with $84.68 \pm 0.22$ of that in FT followed, whereas the one in ABT and ET was $73.14 \pm 0.82$ and $68.71 \pm 0.05$, respectively, revealing that preparation methods significantly affects the pigment change $(\mathrm{p}<0.05)$. $a^{*}$ value indicates greenness to redness and $b^{*}$ value indicates blueness to yellowness. Both of $a^{*}$ and $b^{*}$ in ET was the highest combined with its lowest $L^{*}$ value, suggesting browning occurred during BDF preparation of ET. Conversely, the methods WT and FT could protect the colour from being changed during production of BDF.
TABLE II. THE EFFECT OF PREPARATION METHODS ON COLOUR OF BDF

\begin{tabular}{|l|c|c|c|}
\hline \multirow{2}{*}{$\begin{array}{c}\text { Preparation } \\
\text { Methods }\end{array}$} & $\boldsymbol{L}^{*}$ & $\boldsymbol{a}^{*}$ & $\boldsymbol{b}^{*}$ \\
\cline { 2 - 4 } & $85.02 \pm 0.78^{\mathrm{a}}$ & $2.78 \pm 0.16^{\mathrm{c}}$ & $11.99 \pm 0.29^{\mathrm{c}}$ \\
\hline WT & $73.14 \pm 0.82^{\mathrm{b}}$ & $3.33 \pm 0.11^{\mathrm{b}}$ & $12.79 \pm 0.15^{\mathrm{b}}$ \\
\hline ABT & $84.68 \pm 0.22^{\mathrm{a}}$ & $2.87 \pm 0.11^{\mathrm{c}}$ & $11.75 \pm 0.40^{\mathrm{c}}$ \\
\hline FT & $68.71 \pm 0.05^{\mathrm{c}}$ & $4.83 \pm 0.15^{\mathrm{a}}$ & $15.83 \pm 0.27^{\mathrm{a}}$ \\
\hline ET & \multicolumn{3}{|c|}{ Colour } \\
\hline \multicolumn{2}{|c|}{ Results are the means of three determinations \pm standard deviation. Different letters in the }
\end{tabular}

ame column are significantly different as determined by Duncan's multiple range test $(p<0.05)$

\section{2) WAI and WSI}

WAI and WSI are important quality indexes of dietary fiber. WAI is used to evaluate the water-holding capacity while WSI used to measure the amount of water soluble materials in a sample. Figure 1 displayed the effects of preparation methods on WAI and WSI. It could be obviously found that WAI in ABT and WT were $855.81 \pm$ $33.14 \%$ and $761.39 \pm 24.83 \%$, respectively, higher than that in FT and ET, $721.70 \pm 11.98 \%$ and $625.11 \pm 9.48 \%$, in accordance with the research by $\mathrm{Li}^{[14]}$. However, the tendency of WSI change was significantly different from that of WAI. The ET had the highest value of WSI up to $12.74 \pm 0.69 \%$ with $8.44 \pm 0.52 \%$ in ABT followed, and WT had the poorest value of WSI. The results indicated that there were more water soluble molecules in ET than any other preparations. The water soluble components like SDF would have been lost in boiling and rinsing process, which drove lower WSI in WT. It was reported that the WAI of legume fibers is influenced by the ratio of lignin to polysaccharides, the more lignin the lower $\mathrm{WAI}^{[15]}$. The lignin content of ET was the highest showed in Table I, which accounted for the lowest WAI in ET.

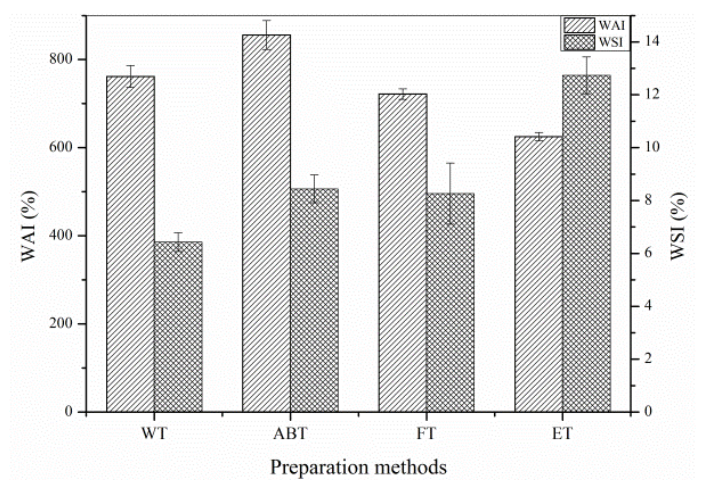

Figure 1. The effect of preparation methods on WAI and WSI of BDF

\section{Structure}

\section{1) Microstructure}

The images of different preparations of dietary fiber from bamboo shoots obtained by SEM are presented in Fig. 2. The microstructure of BDF by using different methods appeared almost similar. The tissue of bamboo shoot was totally damaged in WT because of boiling, homogenizing and grinding process, so the surface was rough, loosened, and porous(Fig. 2 a and b). Acid and alkaline reaction could remove the protein and hemicellulose, leading to the porosity in ABT (Fig. $2 \mathrm{c}$ and d). Fermentation take advantage of microbial metabolism characteristics to get rid of protein, sugar, etc. in dietary fiber, while enzyme 
treatment utilizes the high efficiency and selectivity of enzyme so remove the protein and starch etc.. Hence, although the surface of FT was multihole (Fig. 2 e and f), but the particle was fine and uniform (Fig. $2 \mathrm{~g}$ and $\mathrm{h}$ ), which played an important role in water binding capacity of BDF.

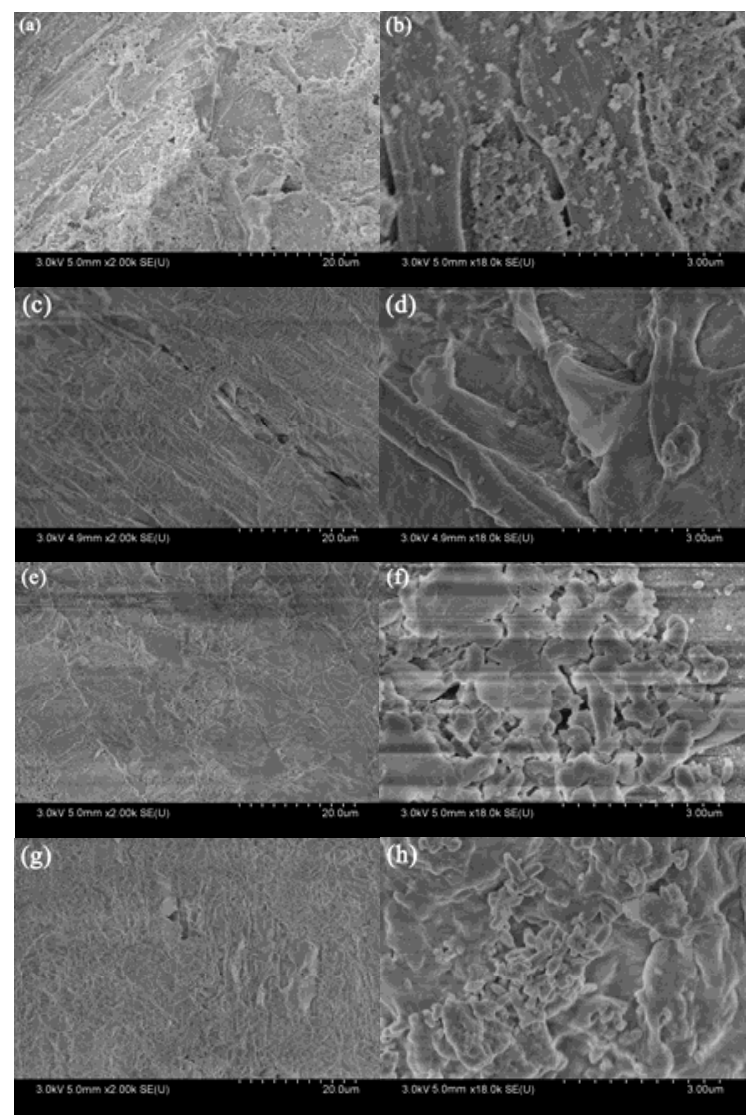

Figure 2. Figure 2. SEM images of BDF with different preparation methods. $(\mathrm{a}, \mathrm{b}) \mathrm{WT}$; (c, d) ABT; $(\mathrm{e}, \mathrm{f}) \mathrm{FT}$; (g, h) ET.

\section{2) Fourier transform infrared spectrum}

Fourier transform infrared spectra of BDF under different preparations were showed in Fig. 3. Obviously, the FT-IR spectra of FT and ET were similar, indicating that they had similar structure. The dominant peaks at 3419 and $2925 \mathrm{~cm}^{-1}$ were due to the $\mathrm{O}-\mathrm{H}$ and $\mathrm{C}-\mathrm{H}$ bands respectively, and corresponded to the aliphatic moieties in lignin, cellulose and hemicellulose ${ }^{[16]}$. The peak in WT and ABT became wide and low, mainly resulted from destruction of hemicellulose in boiling and acid-base treatment. The peak at $1647 \mathrm{~cm}^{-1}$ was associated with adsorbed water and the decrease of the intensity of the peak in WT and ABT was possibly due to the loss of hemicelluloses. A vibration peak at $1538 \mathrm{~cm}^{-1}$ are characteristic peaks of benzene ring, indicating the BDF contained lignin, and the peak of ABT was small, suggesting that lignin fraction was removed in acid-base treatment. The sharp peak at $1377 \mathrm{~cm}^{-1}$ reflected $\mathrm{C}-\mathrm{H}$ asymmetric deformations. The region of $1200-1000 \mathrm{~cm}^{-1}$ represented C-O stretching. The dominant band at $896 \mathrm{~cm}^{-}$ ${ }^{1}$ in BSS fibers indicated the typical structure of cellulose.

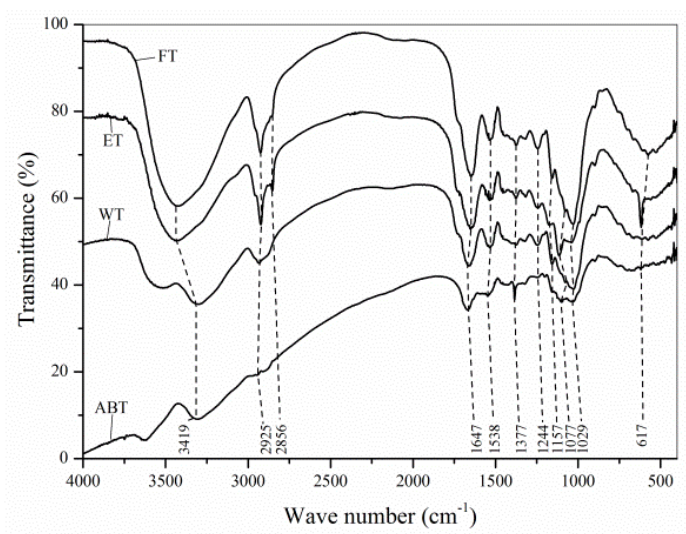

Figure 4. Fourier transform infrared spectra of BDF with different preparation methods.

\section{CONCLUSION}

The preparation of dietary fiber from bamboo shoot will generate great economic benefit, not only because it is widely available, but also due to the cheap price and its excellent quality. Among the four BDF preparation methods, it was generally found that the FT and ET may have a broad developing prospect in the industry to preparing BDF of high quality environmentally. This research also revealed WAI of BDF was higher than most of other dietary fiber, which was important for human body. And more than $50 \%$ of bamboo shoot fiber was hemicellulose, which had the potential to be transformed into SDF.

\section{ACKNOWLEDGMENT}

This research was supported by the Fundamental Scientific Research Funds for Chinese Academy of Tropical Agricultural Sciences (Project No. 1630062014019).

\section{REFERENCES}

[1] T Upreti, R Sundriyal. Indigenous resources and community dependence: a case study from Arunachal Pradesh, India[J]. Grassroots Voices-AJ Resour Dev, 2001, 6(1-2): 28-39.

[2] Y Yuming, W Kanglin, P Shengji, et al. Bamboo diversity and traditional uses in Yunnan, China[J]. Mountain Research and Development, 2004, 24(2): 157-165.

[3] D Choudhury, J K Sahu, G D Sharma. Value addition to bamboo shoots: a review[J]. Journal of Food Science and TechnologyMysore, 2012, 49(4): 407-414.

[4] L M Bal, P Singhal, S Satya, et al. Bamboo shoot preservation for enhancing its business potential and local economy: a review $[\mathrm{J}]$. Critical Reviews in Food Science and Nutrition, 2012, 52(9): 804814.

[5] P Singhal, L M Bal, S Satya, et al. Bamboo shoots: a novel source of nutrition and medicine[J]. Critical Reviews in Food Science and Nutrition, 2013, 53(5): 517-534.

[6] N Chongtham, M S Bisht, S Haorongbam. Nutritional properties of bamboo shoots: potential and prospects for utilization as a health food[J]. Comprehensive Reviews in Food Science and Food Safety, 2011, 10(3): 153-169.

[7] C Nirmala, H Sheena, E David. Bamboo shoots: a rich source of dietary fibres[J]. Dietary fibres, fruit and vegetable consumption and health, Klein F, Moller G (Eds). USA: Nova Science Publishers, 2009: 15-30

[8] E-J Park, D-Y Jhon. Effects of bamboo shoot consumption on lipid profiles and bowel function in healthy young women[J]. Nutrition, 2009, 25(7): 723-728 
[9] W Horwitz. Total, soluble and insoluble dietary fiber in foods[J]. AOAC Official Methods of Analysis, 16th edition., Arlington, Virginia AOAC, 1995: 7-10.

[10] Aoac. Fiber (acid detergent) and lignin in animal feeds. Arlington, VA: Association of Official Analytical Chemists: Official method of analysis of the Association of Official Analytical Chemists, 1990.

[11] P V Van Soest, J Robertson, B Lewis. Methods for dietary fiber, neutral detergent fiber, and nonstarch polysaccharides in relation to animal nutrition[J]. J Dairy Sci, 1991, 74(10): 3583-3597.

[12] J Yang, A Xiao, C Wang. Novel development and characterisation of dietary fibre from yellow soybean hulls[J]. Food chemistry, 2014, 161: 367-375.
[13] E Yamazaki, K Murakami, O Kurita. Easy preparation of dietary fiber with the high water-holding capacity from food sources[J]. Plant foods for human nutrition, 2005, 60(1): 17-23.

[14] L Anping, X Bixia, W Jun, et al. Comparison on the preparation method function and structure of dietary fiber from bamboo shoots[J]. Journal of Chinese Institute of Food Science and Technology, 2010, 10(1): 86-92.

[15] J Bell, A Shires. Composition and digestibility by pigs of hull fractions from rapeseed cultivars with yellow or brown seed coats[J]. Canadian Journal of Animal Science, 1982, 62(2): $557-$ 565.

[16] M Sain, S Panthapulakkal. Bioprocess preparation of wheat straw fibers and their characterization[J]. Industrial Crops and Products, 2006, 23(1): 1-8. 